\title{
Alterations of Cystatin c, Gelsolin, Hepcidin and Sphingosine 1 phosphate in rainbow trout (Oncorhynchus mykiss) with naturally infected Ichthyophthirius multifiliis in Urmia: Determination of Possible Potential Diagnostic Biomarker
}

\author{
Kaveh Azimzadeh $^{1 *}$ (D), Parisa Mohammadisefat ${ }^{2}$ \\ ${ }^{1}$ Islamic Azad University, Veterinary Faculty, Department of Clinical Sciences, Urmia Branch, Urmia, IRAN. \\ ${ }^{2}$ Sari Agricultural Sciences and Natural Resources University, Master of Aquatic Ecology, Sari.
}

\section{How to cite}

Azimzadeh, K., Mohammadisefat, P. (2022). Alterations of Cystatin c, Gelsolin, Hepcidin and Sphingosine 1 phosphate in rainbow trout (Oncorhynchus mykiss) with naturally infected Ichthyophthirius multifiliis in Urmia: Determination of Possible Potential Diagnostic Biomarker, 22(8), TRJFAS19913. http://doi.org/10.4194/TRJFAS19913

\section{Article History}

Received 23 May 2021

Accepted 03 February 2022

First Online 10 February 2022

\section{Corresponding Author \\ Tel.: +989143409583 \\ E-mail: kaclinpath@gmail.com}

\section{Keywords}

Ichthyofetriasis

Rainbow trout

Cystatin c

Gelsulin

Hepsidine

Sphingosine 1 phosphate

\begin{abstract}
Ichthyophthiriasis (white spot disease) is known as one of the most commonly parasites found in overcrowded pools. Cystatin c is known to be the most valuable serum biomarker in determining renal function. Gelsolin is known as an actin-binding protein that eliminates and minimizes blood actin. Regulatory role of hepcidin in iron metabolism and reducing the amount of iron available to microbes plays its antimicrobial role and sphingosine 1 phosphate is able to increase and stimulate antimicrobial activity in host cells. This study was conducted in the summer of 2012 in Urmia, where a number of rainbow trout were collected from eight crowded aquaculture farms. Blood samples were taken from the tail vein of all fish and poured into tubes containing EDTA and significance of the analyzes was set the level $(\mathrm{P}<0.01)$. According to the results, cystatin $\mathrm{c}$, hepcidin and sphingosine 1 phosphate in infected fish were significantly increased compared to healthy fish, while the gelsolin level was significantly reduced. In conclusion, based on ROC statistical analysis, "hepcidin" has high sensitivity (88.6\%) than other ones and it means that, hepcidin may utilize as "Possible Potential Diagnostic Biomarker" in rainbow trout Ichthyophthiriasis.
\end{abstract}

\section{Introduction}

Ichthyophthiriasis (white spot disease, Ich) usually plays an important role in the severity of mortality and economic losses in freshwater aquatic fish parasitic diseases in tropical, subtropical and temperate regions, which belongs to the protozoan parasite (Ichthyophthirius multifiliis) and is known as one of the most pathogenic parasites [Mifsud and Rowland, 2008]. Congestion stress facilitates the occurrence of a disease and consequently suppresses the immune system of fish. In other words, it increases the incidence of bacterial diseases in fish [Witeska et al., 2010].
Cystatin c is a small protein that belongs to the cysteine protease inhibitors. This protein is continuously produced in all nucleotide cells and is released into the bloodstream and has a half-life of 2 hours [Villa et al., 2005]. This protein is independently filtered by glomeruli in the kidneys and reabsorbed and recatalyzed in the proximal tubules [Antognoni et al., 2007]. Cystatin c is known as the most valuable serum biomarker in determining renal function, especially a good choice for knowing the amount of glomerular filtration [Lassus and Harjola, 2012].

Gelsolin is found extracellularly in plasma and intracellularly in cytoplasm and mitochondria 
[Azimzadeh et al., 2019]. Gelsolin is known as an actinbinding protein that is involved in the removal of extracellular actin subsequently in tissue damage [Sun et al., 1999].

With studying the antimicrobial properties of various human body fluids, they isolated a small peptide from human urine and named it hepcidin based on its hepatic synthesis site and antibacterial properties in the body (cidin) [Park et al., 2001]. Hepcidin is a small and cationic peptide of 25 amino acids, has 4 intramolecular disulfide bonds and its dominant and active form in serum and biological fluids is in the form of hepsidine25 , which is composed of amino acids [Ganz, 2003]. This peptide exerts its regulatory function by neutralizing the function of ferroportine, which is expressed at the level of macrophages, hepatocytes, and enterocytes, thereby increasing intracellular iron stores, reducing nutrient iron uptake, and decreasing circulating iron concentrations. In addition to the regulatory role in iron metabolism, hepcidin plays its antimicrobial role by reversing the direction of inflammatory responses and reducing the amount of iron available to microbes [Kanda et al., 2008; Lauth et al., 2005].

Sphingosine 1-phosphate is a bio-active lipid mediator that belongs to the group of sphingolipids and participates in both physiological and pathophysiological pathways [Nofer, 2008]. Sphingosine 1-phosphate is abundant in plasma and other body fluids and plays an important role in cell function through autocrine or paracrine pathways [Hanel et al., 2007]. Red blood cells and platelets are involved in the storage and secretion of sphingosine 1 phosphate and are known to be the main sources of sphingosine 1 phosphate. In addition, sphingosine 1-phosphate plays an important role in the extraction of lymphocytes from secondary lymphatic tissues to lymph. It is also claimed that sphingosine 1 phosphate is able to increase and stimulate antimicrobial activity in host cells [Garg et al., 2004].

To our knowledge, no published literatures have been performed about alterations of above mentioned parameters and determination of possible potential biomarker in rainbow trout with ichthyophthiriasis.

\section{Materials and methods}

This study was conducted in Urmia. In Seventy rainbow trout at the one of the eight aquaculture farms (crowded), observed severe infection with parasites in the form of horseshoe kernels on the head, fins and gills with white spots and the ciliated protozoan (Ichthyophthirius multifiliis) was observed under microscope. The same number (seventy) of fish without parasite and symptoms of other diseases were identified as a healthy group. Anesthesia has not been performed in fish due to possible side-effects on blood parameters [McKnight, 1966] and all blood sampling were obtained based on Canadian Council on Fisheries and Oceans Animal Care ethical board (CCAC). Blood samples were taken from the tail vein of all fish and poured into tubes containing EDTA for plasma preparation. All tubes were then centrifuged at room temperature $\left(21^{\circ} \mathrm{C}\right)$ at 4,000 rpm for 10 minutes and stored at $-18^{\circ}{ }^{\circ}$. The concentration of gelsolin and cystatin c was determined with the ELISA kit (Elab Science Biotechnology Company, South Africa) and the concentration of hepcidin was measured with the ELISA kit (Mybiosource Company, USA). Plasma sphingosine 1 phosphate concentration was measured with ELISA kit (bioassay, Technology Laboratory, China). Also, in terms of statistical analysis, $t$-student test, Pearson Correlation's test and ROC analysis (Receiver Operating Curve) for analysis of cut of point and determination of "Sensitivity-Specificity" were performed for all data by SPSS statistical software version 22 and the significance of the analysis was done at the level $(P<0.01)$.

\section{Result}

Table 1 shows the comparison of changes in plasma parameters in the parasite-infected group with the group without parasitic infection. Accordingly, the results showed that the mean parameters of cystatin c, hepcidin, sphingosine 1 phosphate in infected rainbow trout had a significant increase $(P<0.01)$. In contrast, gelsolin levels were significant low in the parasiteinfected group than healthy ones $(P<0.01)$.

In Table 2: Based on ROC analysis, all parameters have good specificity, but in terms of sensitivity, there is difference between parameters, the higher sensitivity belongs to "hepcidin" with $88.6 \%$.

According to Table 3, all parameters have a significant positive and negative correlation with each other at the level of 0.01 . A positive two-way correlation between parameters means that the parameters interact with each other, i.e with the increase or decrease of each parameter, the other parameter also increases or decreases. Negative two-way correlation

Table 1. Alterations of plasma parameters in the infected group compared to the healthy ones

\begin{tabular}{ccc}
\hline Plasma parameter & Control group (without parasitic infection) & Patient group (naturally infected with parasite) \\
\hline Cystatin c & $12.94 \pm 1.36$ & $54.16 \pm 6.90^{\dagger}$ \\
Hepcidin & $130.78 \pm 13.55$ & $382.41 \pm 26.14^{\dagger}$ \\
Sphingosine 1 phosphate & $71.48 \pm 9.87$ & $259.87 \pm 18.22^{\dagger}$ \\
Gelsolin & $138.47 \pm 12.49$ & $19.87 \pm 1.63^{\dagger}$ \\
\hline
\end{tabular}

Numbers are based on the mean \pm standard deviation expressed, $\uparrow$ shows a significant difference with the control group 
Table 2. ROC (AUC) analysis of parameters

\begin{tabular}{|c|c|c|c|c|c|c|c|c|}
\hline \multirow{3}{*}{$\frac{\text { Parameter }}{\text { Cystatin C }}$} & \multirow{3}{*}{$\begin{array}{l}\text { AUC } \\
.983\end{array}$} & \multirow{3}{*}{$\frac{\text { Cut-off }}{53.156}$} & \multirow{3}{*}{$\begin{array}{c}\text { Sensitivity } \\
.857\end{array}$} & \multirow{3}{*}{$\frac{\text { Specificity }}{\text { More than } 0.999}$} & \multirow{3}{*}{$\frac{\text { Std. Error }}{.011}$} & \multirow{3}{*}{$\frac{\text { Asymptotic Sig. }}{\text { less than } 0.001}$} & \multirow{2}{*}{\multicolumn{2}{|c|}{$\begin{array}{c}\text { 95\% asymptotic } \\
\text { confidence interval } \\
\text { Lower Bound Upper Bound }\end{array}$}} \\
\hline & & & & & & & & \\
\hline & & & & & & & .962 & 1.000 \\
\hline Hepcidin & .988 & 383.491 & .886 & More than 0.999 & .009 & less than 0.001 & .971 & 1.000 \\
\hline $\begin{array}{l}\text { Sphingosine. } \\
\text { 1.phosphate }\end{array}$ & .980 & 269.700 & .829 & More than 0.999 & .012 & less than 0.001 & .956 & 1.000 \\
\hline Gelsolin & .841 & 161.066 & .029 & More than 0.999 & .060 & less than 0.001 & .724 & .958 \\
\hline
\end{tabular}

Table 3. The two-by-two distribution diagram of each of the parameters is shown below

\begin{tabular}{|c|c|c|c|c|c|}
\hline & & Cystatin C & Hepcidin & Esfengosin.1.fosfat & Gelsolin \\
\hline \multirow{3}{*}{ Cystatin C } & Pearson correlation & 1 & $.662^{* *}$ & $.668^{* *}$ & $-.634^{* *}$ \\
\hline & Significance level & & Less than .001 & Less than .001 & Less than .001 \\
\hline & Number & 70 & 70 & 70 & 70 \\
\hline \multirow{3}{*}{ Hepcidin } & Pearson correlation & $.662^{* *}$ & 1 & & $-.715^{* *}$ \\
\hline & Significance level & Less than .001 & $\underline{ }$ & Less than .001 & Less than .001 \\
\hline & Number & 70 & $\overline{70}$ & 70 & 70 \\
\hline \multirow{3}{*}{ Esfengosin.1.fosfat } & Pearson correlation & $.668^{* *}$ & $.739^{* *}$ & 1 & $-.656^{* *}$ \\
\hline & Significance level & Less than .001 & Less than .001 & & Less than .001 \\
\hline & Number & 70 & 70 & 70 & 70 \\
\hline \multirow{3}{*}{ Gelsolin } & Pearson correlation & $-.634^{* *}$ & $-.715^{* *}$ & $-.656^{* *}$ & 1 \\
\hline & Significance level & Less than .001 & Less than .001 & Less than .001 & L \\
\hline & Number & 70 & 70 & 70 & 70 \\
\hline
\end{tabular}

between parameters means that the parameters do not interact with each other, that is, by increasing or decreasing each of the parameters, the other parameter decreases or increases. The highest and lowest positive correlations were between the parameters of "hepcidin and sphingosine 1 phosphate with a significant size of 0.739 " and the parameters of "cystatin C with hepcidin with a significant size of 0.662 ", respectively.

The highest and lowest negative correlations are between the parameters of "gelsolin and hepcidin; with a significant size of -0.715 and the parameters of "gelsolin with cystatin C; with a significant size of -0.634 .

\section{1) Student $t$-test Statistical Analysis Figures:}

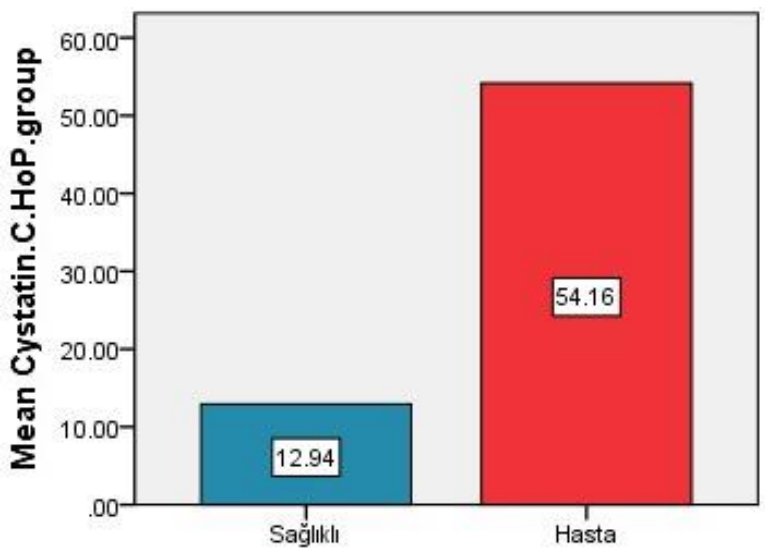

Fishes.HoP

Figure 1. Bar chart of Cystatin $C$ in healthy and disease fish. (Student $t$-test).

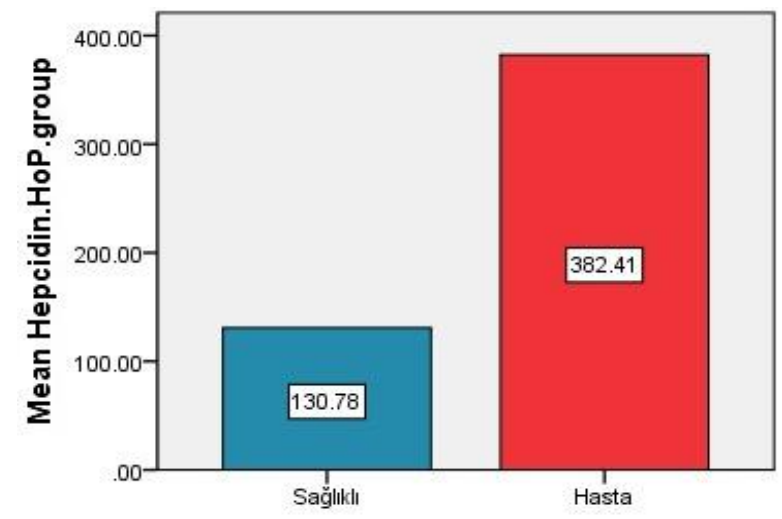

Fishes.HoP

Figure 2. Bar chart of Hepcidin in healthy and disease fish. (Student t-test).

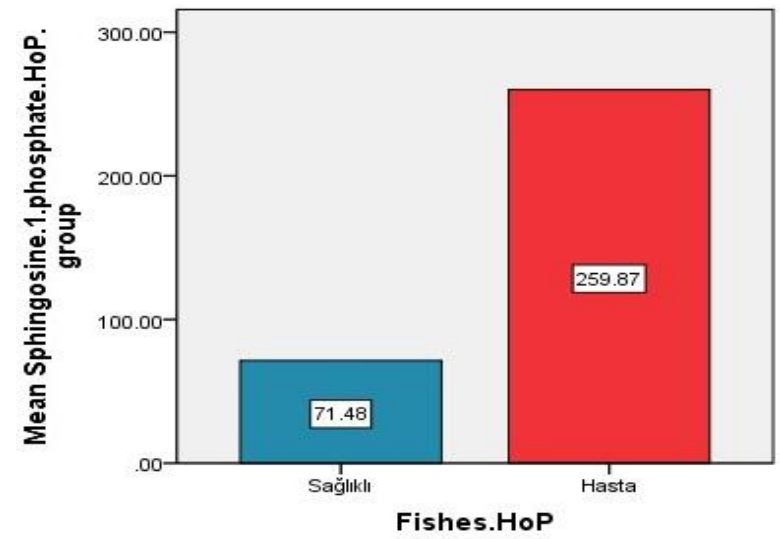

Figure 3. Bar chart of Sphingosine 1 phosphate in healthy and disease fish. (Student t-test). 


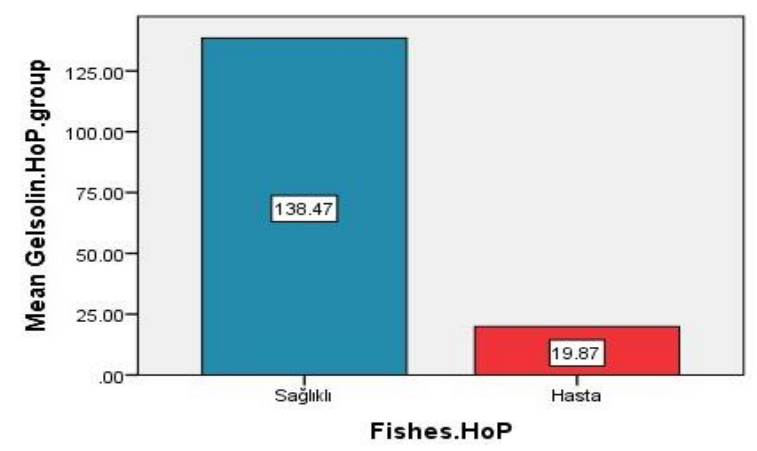

Figure 4. Bar chart of Gelsolin in healthy and disease fish. (Student t-test).

\section{2) Receiver Operating Characteristic Curve (ROC) Statistical Analysis Figures:}

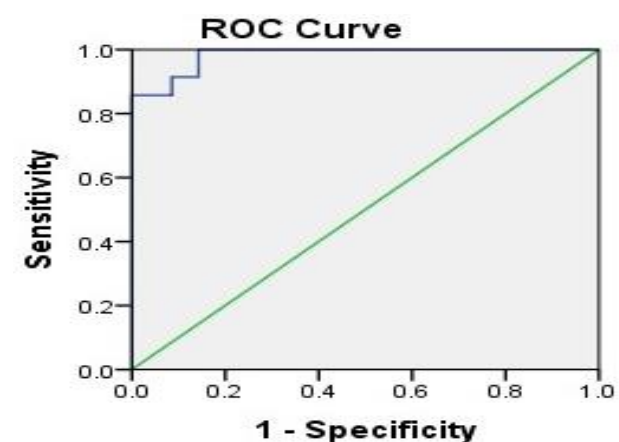

Figure 5. ROC analysis with Area Under Curve (AUC) in Cystatin.

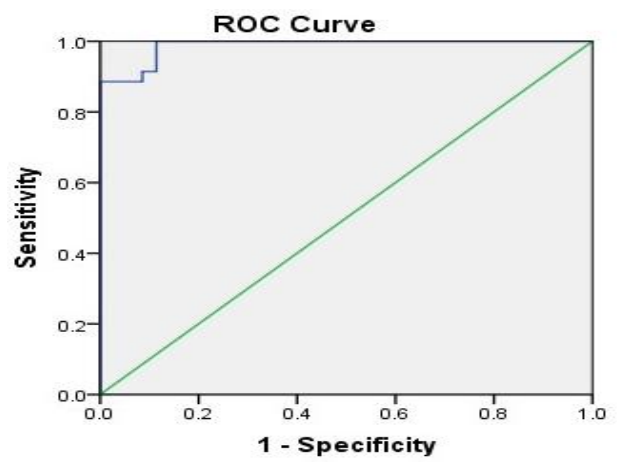

Figure 6. ROC analysis with Area Under Curve (AUC) in Hepcidin.

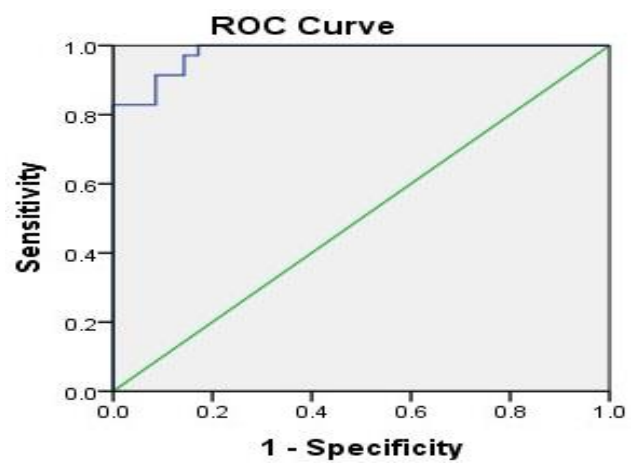

Figure 7. ROC analysis with Area Under Curve (AUC) in Sphingosine 1 Phosphate.

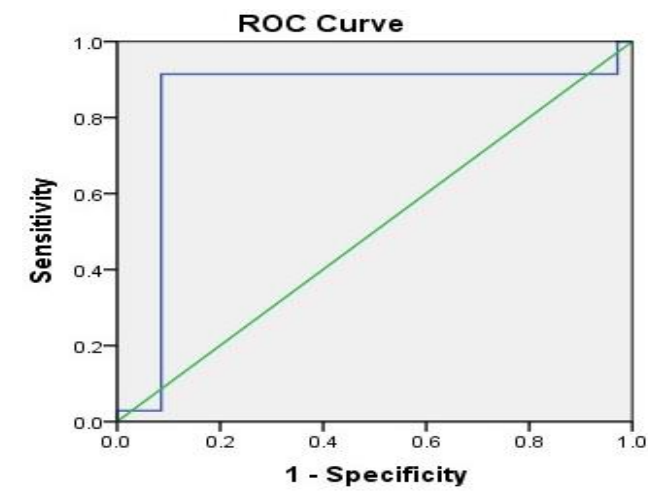

Figure 8. ROC analysis with Area Under Curve (AUC) in Gelsolin.

3) Pearson`s Correlation Statistical Analysis Figures:

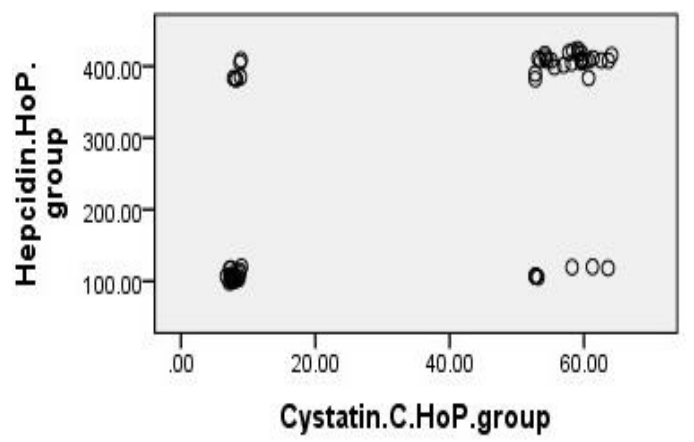

Figure 9. Distribution Chart of Correlation between Cystatin c and Hepcidin.

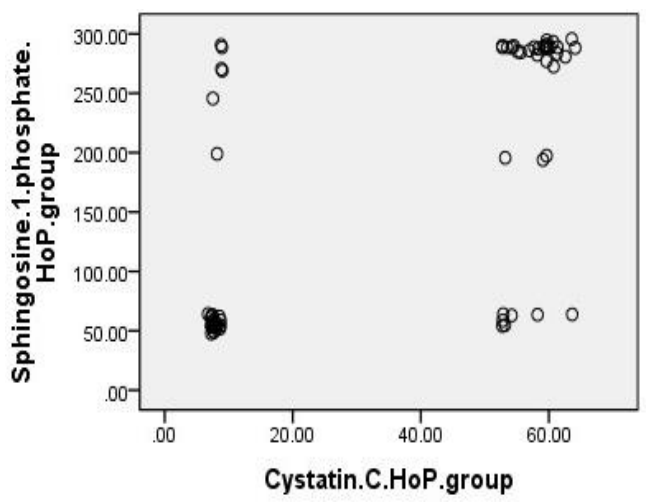

Figure 10. Distribution Chart of Correlation between Cystatin $\mathrm{c}$ and Sphingosine 1 phosphate.

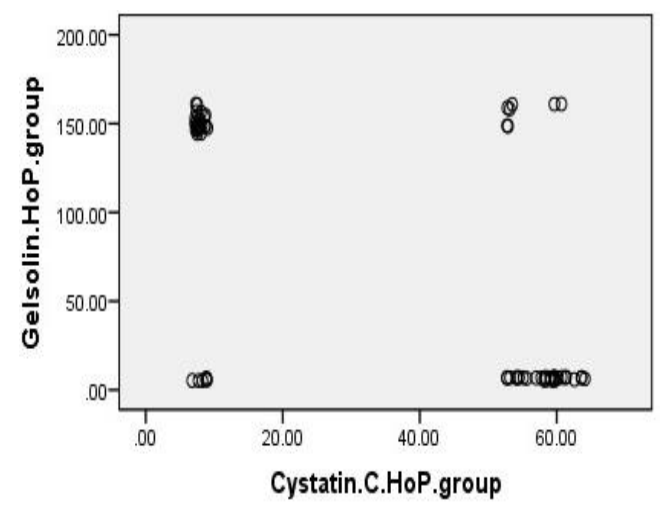

Figure 11. Distribution Chart of Correlation between Cystatin c and Gelsolin. 


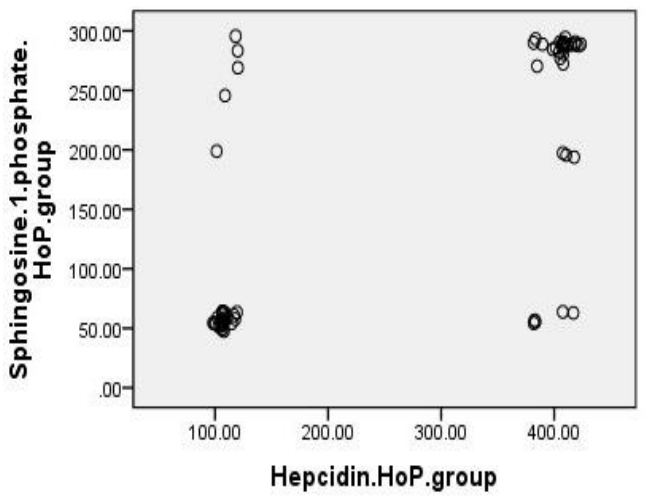

Figure 12. Distribution Chart of Correlation between Hepcidin and Sphingosine 1 phosphate.

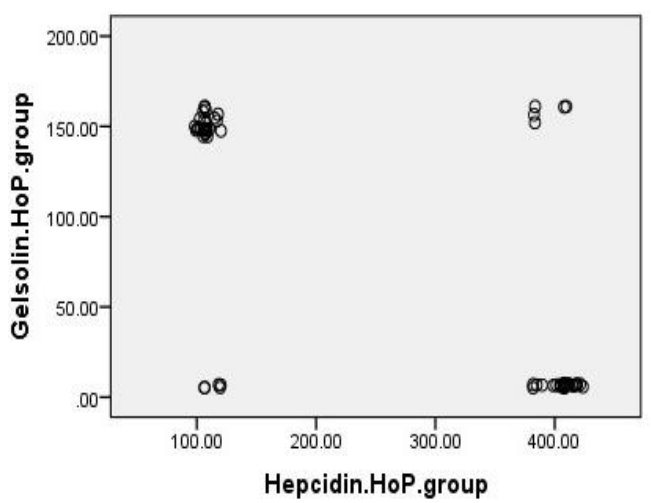

Figure 13. Distribution Chart of Correlation between Hepcidin and Gelsolin.

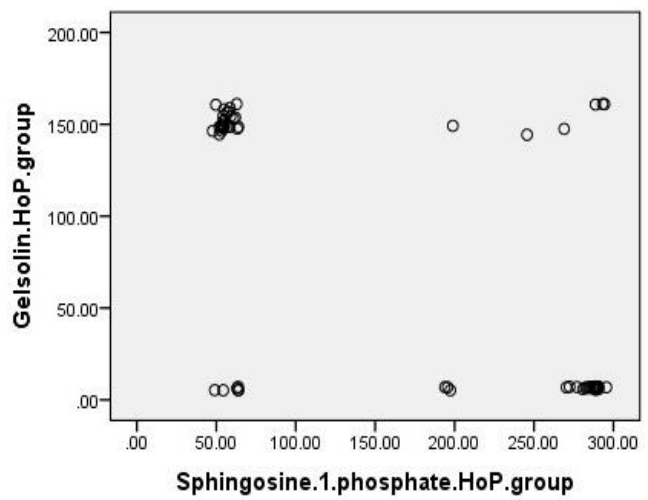

Figure 14. Distribution Chart of Correlation between Sphingosine 1 phosphate and Gelsolin.

\section{Discussion}

The substantial effects of S1P has been determined on the function of $\mathrm{T}$ and $\mathrm{B}$ lymphocytes which is included in the maturation and migration of them. It plays especially as a substantial effect onto activation of T cell [Azimzadeh et al., 2017; Hait et al., 2006]. It has been demonstrated that during the $\mathrm{T}$ and $\mathrm{B}$ lymphocytes activation and stimulation, subsequently, S1P synthesis is reduced [Guo et al., 2013] which is not in accordance with our evidence. one of the possible causes of augmentation of S1P may be related to its stimulating role in the maturation and rapid migration of lymphocytes particularly $\mathrm{T}$ cells during infection. Besides, the role of S1P in stimulation and regulation of the antimicrobial activity of immune cells has been determined in in-vivo and in-vitro conditions [Garg et al., 2004]. Thus, it is probable that S1P increases in order to stimulate and regulate the metabolic pathways of defensive cells against the pathogen. Another possible cause can be attributed to an increase in blood HDL levels because firstly S1P is considered as a component of the structure of HDL and secondly, one of the known effects of HDL is its protective role against infection as HDL can bind to the bacterial lipopolysaccharide and finally eliminates and neutralizes it [Guo et al., 2013]. Thus, it is possible that HDL synthesis has increased to eliminate the parasitic antigens released from Ichthyophthirius multifiliis and subsequently the concentration of S1P has been elevated in the infected group. We could not find any evidence which related to S1P alterations in Ichthyophthiriasis. Li et al. [Li et al., 2009] showed that S1P concentration to be increased in CCL4-mediated hepatic fibrosis in rat which is in accordance with our study. Ikeda et al., in 2010 showed S1P reduction in liver fibrosis patients that is not consistent with our evidence. Platelets are known to be one of the main sources of S1P in plasma during sphingosine phosphorylation by sphingosine kinase [Pappu, 2007; Yatomi et al., 1995]. In line with this, platelets are recognized to reserve S1P plentifully and after activation, release it into the plasma [Toghill and Green, 1983]. In the respect of platelets, it might be activated in rainbow trout with Ichthyophthiriasis which could cause S1P elevation. Furthermore, it is possible that plasma S1P may be raised due to unknown source(s) which need further clarified.

Our data showed that the plasma hepcidin in the infected and non-infected ones was higher than the control group. Generally, infection induces the synthesis and secretion of hepcidin in order to decrease the bioavailability of iron [Azimzadeh and Izadmehr, 2017]. Although previous studies have reported the involvement of hepcidin in infection and experimental inflammation [Cuesta et al., 2008; Galesloot et al., 2011]. It has been reported that the level of serum hepcidin increases in pneumonia, infection, and pyelonephritis and it should be noted that IL- 6 increases the synthesis and secretion of hepcidin in various diseases [Wang et al., 2013]. Consistent with our data, Li et al in 2021 reported that hepcidin level is increased in rainbow trout affected with Ichthyophthirius multifiliis. Hepcidin synthesis is regulated by inflammatory cytokines and iron concentration in circulating blood; therefore, hepcidin reduces ferroportin and availability of iron [Noguchi-Sasaki et al., 2016]. As hepcidin is critically involved in innate immunity by its direct antimicrobial properties and by reducing the bioavailability of iron [Azimzadeh and Izadmehr, 2017; Cuesta et al., 2008; Sow et al., 2011], thus, it is likely that hepcidin expression has been enhanced in the infected group due to infection with Ichthyophthirius multifiliis, 
by decreasing the bioavailability of iron. Besides, the possibility exists that hepcidin expression may be induced in infected group through unknown mechanisms.

Gelsolin (GLS) is known as actin binding protein which eliminates and minimizes blood actin which is subsequently produced during various diseases induced tissue damage especially hematologic ones, either directly (affects the blood cells) or indirectly (involvement in organs involved in hematopoiesis). Excessive release of actin into the blood, leads to a remarkable reduction of GLS which is not appropriate prognosis for amelioration of disease. So we can say that plasma GLS is associated with the disease severity and prognosis and therefore, it is under consideration as a prognostic indicator in acute diseases. In this study, plasma GLS decreased in disease group than healthy ones. In a study, GLS reduction was observed in hepatitis $B$ patients and they reported it as possible diagnostic biomarker for detection of severity of hepatic injury [Mei et al., 2021]. Furthermore, GLS reduction demonstrated during brain hemorrhage [Zhao et al., 2013]. Since GLS reduction in plasma occurred following actin increase in the blood, thus most likely it can be said that during with Ichthyophthirius multifiliis-mediated infection, cell damage occurred in various tissues and finally, this mechanism increases the synthesis and secretion of GLS into blood to inhibit actin which led to a reduction in the plasma GLS in infected group. These findings correspond with the results of our research.

By assessing the serum Cys c levels in healthy and infected groups, we found that the mean serum level of this parameter in the infected group was higher than healthy one. There is no study on this parameter in rainbow trout affected Ichthyophthiriasis, but in one report with leishmaniosis, Cys c level was increased in comparison to the healthy group [Pasa et al., 2009] and even demonstrated Cys $c$ as a new biomarker in early detection of renal injury in dogs and finally Azimzadeh in 2017 reported high Cys c level in sheep theileriosis with different parasitemia rates. Since blood parasites such as Leishmania, causes tissue damage by forming immune-complexes (immunopathologic mechanisms), especially in the kidney, it is likely that Ichthyophthiriasis causes kidney damage by same mechanism (especially kidney glomeruli) and eventually leads to an increase in Cys $\mathrm{c}$ in serum.

In conclusion, ichthyophthiriasis accompanies in alterations of some plasma parameters and causes severe tissue damage along with stimulation of inflammatory and antimicrobial defense reactions.

\section{Ethical Statement}

Not applicable.

\section{Funding Information}

Work supported by UNIVERSITY AZAD OF URMIA.

\section{Author Contribution}

First Author: Conceptualization editing; Data Curation, Formal Analysis, Methodology, Visualization Second Author: Writing -original draft, Writing -review and editing.

\section{Conflict of Interest}

Kaveh Azimzadeh and parisa mohammadisefat declare that they have no known competing financial or non-financial, professional, or personal conflicts that could have appeared to influence the work reported in this paper.

\section{Acknowledgements}

Thanks to University Azad of Urmia for supports.

\section{References}

Antognoni, M.T., Siepi, D., Porciello, F., Rueca, F., \& Fruganti, G. (2007). Serum Cystatin-C Evaluation in Dogs Affected by Different Diseases Associated or not with Renal Insufficiency. Veterinary Research Communications, 31(1), 269-271. https://doi.org/10.1007/s11259-0070044-1

Azimzadeh, K., Nargesabad, R.N., \& Vousooghi, N. (2017). Evaluation of plasma sphingosine 1-phosphate, hepcidin and cardiovascular damage biomarkers (cardiac troponin I and homocysteine) in rats infected with brucellosis and vaccinated (Rev-1, RB-51). Microbial pathogenesis, 109, 67-70. https://doi.org/10.1016/j.micpath.2017.05.031

Azimzadeh, K., Mahan, M., HERGALANI, N.Z., \& Zahed, T. (2019). Determination of Possible Potential Biomarker Between Plasma Arginase, Gelsolin and Cystatin C in Sheep Babesiosis: Based on Parasitemia Rate. Atatürk Üniversitesi Veteriner Bilimleri Dergisi, 14(1), 1-7. https://doi.org/10.17094/ataunivbd.367320

Azimzadeh, K., \& Izadmehr, S. (2017). Evaluation of Plasma Hepcidin, Cystatin-C and Gelsolin in Ovine Theileriosis (Ghezel Breed) Based On Age and Parasitemia Rate. https://doi.org/10.16988/iuvfd.268662

Cuesta, A., Meseguer, J., \& Esteban, M.A. (2008). The antimicrobial peptide hepcidin exerts an important role in the innate immunity against bacteria in the bony fish gilthead seabream. Molecular immunology, 45(8), 2333 2342. https://doi.org/10.1016/j.molimm.2007.11.007

Ganz T. (2003). Hepcidin, a key regulator of iron metabolism and mediator of anemia of inflammation. Blood; 102:783-88. https://doi.org/10.1182/blood-2003-03-0672

Garg, S.K., Volpe, E., Palmieri, G., Mattei, M., Galati, D., Martino, A., ... \& Fraziano, M. (2004). Sphingosine 1phosphate induces antimicrobial activity both in vitro and in vivo. The Journal of infectious diseases, 189(11), 2129-2138. https://doi.org/10.1086/386286

Guo, L., Ai, J., Zheng, Z., Howatt, D.A., Daugherty, A., Huang, B., \& Li, X.A. (2013). High density lipoprotein protects against polymicrobe-induced sepsis in mice. Journal of Biological chemistry, 288(25), 17947-17953. https://doi.org/10.1074/jbc.m112.442699 
Galesloot, T.E., Vermeulen, S.H., Geurts-Moespot, A.J., Klaver, S.M., Kroot, J.J., van Tienoven, D., ... \& Swinkels, D.W. (2011). Serum hepcidin: reference ranges and biochemical correlates in the general population. Blood, The Journal of the American Society of Hematology, 117(25), e218-e225. https://doi.org/10.1182/blood2011-02-337907

Hait, N.C., Oskeritzian, C.A., Paugh, S.W., Milstien, S., \& Spiegel, S. (2006). Sphingosine kinases, sphingosine 1phosphate, apoptosis and diseases. Biochimica et Biophysica Acta (BBA)-Biomembranes, 1758(12), 20162026. https://doi.org/10.1016/j.bbamem.2006.08.007

Hänel, P., Andréani, P., \& Gräler, M.H. (2007). Erythrocytes store and release sphingosine 1-phosphate in blood. The FASEB Journal, 21(4), 1202-1209. https://doi.org/10.1096/fj.06-7433com

Ikeda, H., Ohkawa, R., Watanabe, N., Nakamura, K., Kume, Y., Nakagawa, H., ... \& Yatomi, Y. (2010). Plasma concentration of bioactive lipid mediator sphingosine 1phosphate is reduced in patients with chronic hepatitis C. Clinica chimica acta, 411(9-10), 765-770. https://doi.org/10.1016/j.cca.2010.02.063

Kanda, J., Mizumoto, C., Kawabata, H., Tsuchida, H., Tomosugi, N., Matsuo, K., \& Uchiyama, T. (2008). Serum hepcidin level and erythropoietic activity after hematopoietic stem cell transplantation. haematologica, 93(10), 15501554. https://doi.org/10.3324/haematol.12399

Lassus, J., \& Harjola, V.P. (2012). Cystatin C: a step forward in assessing kidney function and cardiovascular risk. Heart failure reviews, 17(2), 251-261. https://doi.org/10.1007/s10741-011-9242-6

Lauth, X., Babon, J.J., Stannard, J.A., Singh, S., Nizet, V., Carlberg, J.M., ... \& Westerman, M.E. (2005). Bass hepcidin synthesis, solution structure, antimicrobial activities and synergism, and in vivo hepatic response to bacterial infections. Journal of Biological Chemistry, 280(10), 9272-9282. https://doi.org/10.1074/jbc.m411154200.

Li, C., Jiang, X., Yang, L., Liu, X., Yue, S., \& Li, L. (2009). Involvement of sphingosine 1-phosphate (SIP)/S1P3 signaling in cholestasis-induced liver fibrosis. The American journal of pathology, 175(4), 1464-1472. https://doi.org/10.2353/ajpath.2009.090037.

Li, X., Jaafar, R., Yang, H., Boqian, W., Kania, P., Buchmann, K. (2021). Effects of a Pseudomonas H6 surfactant on rainbow trout and Ichthyophthirius multifiliis: In vivo exposure. https://doi.org/10.1016/j.aquaculture.2021.737479

Mei, L., Sujun, Z., Shengbin, X., Enyun, S., Hao, Y., Peng, C., ... \& Zhongping, D. (2012). Predictive value of serum gelsolin in hepatitis B virus (HBV)-related chronic liver disease. African Journal of Biotechnology, 11(20), 46404645 https://doi.org/10.1016/s0168-8278(86)80436-6

Mifsud, C., \& Rowland, S.J. (2008). Use of salt to control ichthyophthiriosis and prevent saprolegniosis in silver perch, Bidyanus bidyanus. Aquaculture Research, 39(11), 1175-1180. Atluri, S.N. and Shen, S. (2002), "The Meshless Local Petrov-Galerkin (MLPG) Method", Tech Science Press, USA. https://doi.org/10.1111/j.1365-2109.2008.01981.x

McKnight, I.M. (1966). A hematological study on the mountain whitefish, Prosopium williamsoni. Journal of the Fisheries Board of Canada, 23(1), 45-64. https://doi.org/10.1139/f66-005

Nofer, J.R. (2008). High-density lipoprotein, sphingosine 1phosphate, and atherosclerosis. Journal of clinical lipidology, 2(1), 4-11. https://doi.org/10.1016/j.jacl.2007.11.002

Noguchi-Sasaki, M., Sasaki, Y., Shimonaka, Y., Mori, K., \& Fujimoto-Ouchi, K. (2016). Treatment with anti-IL-6 receptor antibody prevented increase in serum hepcidin levels and improved anemia in mice inoculated with IL6-producing lung carcinoma cells. BMC cancer, 16(1), 111. https://doi.org/10.1186/s12885-016-2305-2

Pappu, R. (2007). Schwab SR, Cornelissen I, Pereira JP, Regard JB, Xu Y, Camerer E, Zheng YW, Huang Y, Cyster JG, Coughlin SR. Promotion of lymphocyte egress into blood and lymph by distinct sources of sphingosine-1phosphate. Science, 316, 295-298. https://doi.org/10.1126/science.1139221

Park, C.H., Valore, E.V., Waring, A.J., \& Ganz, T. (2001). Hepcidin, a urinary antimicrobial peptide synthesized in the liver. Journal of biological chemistry, 276(11), 78067810. https://doi.org/10.1074/jbc.m008922200

Pasa, S., Bayramli, G., Atasoy, A.B.i.D.i.N., Karul, A., Ertug, S., \& Toz, S.O. (2009). Evaluation of serum Cystatin-C in dogs with visceral leishmaniasis. Veterinary research communications, 33(6), 529-534. https://doi.org/10.1007/s11259-008-9200-5

Sow, F.B., Nandakumar, S., Velu, V., Kellar, K.L., Schlesinger, L.S., Amara, R.R., ... \& Sable, S.B. (2011). Mycobacterium tuberculosis components stimulate production of the antimicrobial peptide hepcidin. Tuberculosis, 91(4), 314321. https://doi.org/10.1016/j.tube.2011.03.003

Sun, H.Q., Yamamoto, M., Mejillano, M., \& Yin, H.L. (1999). Gelsolin, a multifunctional actin regulatory protein. Journal of Biological Chemistry, 274(47), 33179-33182. https://doi.org/10.1074/jbc.274.47.33179

Toghill, P.J., \& Green, S.H.E.I.L.A. (1983). Platelet dynamics in chronic liver disease using the 111Indium oxine label. Gut, 24(1), 49-52. https://doi.org/10.1136/gut.24.1.49

Villa, P., Jiménez, M., Soriano, M.C., Manzanares, J., \& Casasnovas, P. (2005). Serum cystatin C concentration as a marker of acute renal dysfunction in critically ill patients. Critical Care, 9(2), 1-5. https://doi.org/10.1186/cc3044

Witeska, M., Kondera, E., \& Lugowska, K. (2010). The effects of ichthyophthiriasis on some haematological parameters in common carp. Turkish Journal of Veterinary and Animal Sciences, 34(3), 267-271.

Wang, X.H., Cheng, P.P., Jiang, F., Jiao, X.Y. (2013). The effect of hepatitis $B$ virus infection on hepcidin expression in hepatitis B patients, Annual Clinical. Laboratory Science. 43: $126 \mathrm{e} 134$ https://doi.org/10.1097/pec.0b013e318294f3a5

Yatomi, Y., Ruan, F., Hakomori, S.I., \& Igarashi, Y. (1995). Sphingosine-1-phosphate: a platelet-activating sphingolipid released from agonist-stimulated human platelets.

https://doi.org/10.1182/blood.v86.1.193.bloodjournal8 61193

Zhao, D.Q., Wang, K., Zhang, H.D., \& Li, Y.J. (2013). Significant reduction of plasma gelsolin levels in patients with intracerebral hemorrhage. Clinica Chimica Acta, 415, 202-206. https://doi.org/10.1016/j.cca.2012.10.048 